\title{
GCU
}

Glasgow Caledonian

University

University for the Common Good

\section{Learning on the job? Exploring first-year experiences of newly-qualified criminal justice social workers in Scotland}

Grant, Scott

Published in:

Probation Journal

DOI:

10.1177/0264550516682106

Publication date:

2017

Document Version

Author accepted manuscript

Link to publication in ResearchOnline

Citation for published version (Harvard):

Grant, S 2017, 'Learning on the job? Exploring first-year experiences of newly-qualified criminal justice social workers in Scotland', Probation Journal, vol. 64, no. 1, pp. 33-49. https://doi.org/10.1177/0264550516682106

\section{General rights}

Copyright and moral rights for the publications made accessible in the public portal are retained by the authors and/or other copyright owners and it is a condition of accessing publications that users recognise and abide by the legal requirements associated with these rights.

Take down policy

If you believe that this document breaches copyright please view our takedown policy at https://edshare.gcu.ac.uk/id/eprint/5179 for details of how to contact us. 


\title{
Learning on the job? Exploring first-year experiences of newly-qualified criminal justice social workers in Scotland
}

\begin{abstract}
Little is known about the experiences of newly-qualified criminal justice practitioners as they enter the field of community justice for the first time. This article reports on isolated data on newly-qualified criminal justice social workers who participated in a national mixed-method study of readiness to practice in Scotland. Findings suggest that new staff felt well-prepared for practice, but many felt employers failed to provide adequate support and development opportunities. Participants report that disproportionate emphasis is placed on workload management during professional supervision sessions where learning needs and emotions are often underplayed. Professional guidance is often sought from informal sources.
\end{abstract}

\section{Keywords}

Criminal justice social workers, professional socialisation, practice cultures, readiness, training, professional development.

\section{Introduction}

Just how community-based criminal justice practitioners are constituted ought to matter more to criminal justice policy makers and scholars of punishment. When 'reducing reoffending' is declared a national policy objective in most European jurisdictions, and when numbers of those made subject to community sanctions and measures continue to rise at unprecedented rates (see Robinson and McNeill, 2016), frontline staff are left with the practical (and some might add political) task of translating penal policy into everyday penal practice (Garland, 2001). Meanwhile criminologists still continue to wrestle with the implications of 'mass incarceration' in contemporary society, when new and emerging evidence suggests that 'mass supervision' is becoming a key challenge to the supremacy of the prison as the primary mode of penal punishment (see Phelps, 2016; Robinson, 2016). Faced with this exceptional penal tilt, criminal justice staff, i.e. those who work in organisations tasked with delivering various forms of punishment in community sites, remain significantly under-researched in contrast to staff based in prison settings (for example, see Crewe, 2011; Lerman and Page, 2012; Liebling, 2000). Indeed, few empirical studies focus specifically on those who work in areas of community punishment (Burke and Davies, 2011), leaving scholars with limited understandings of who these staff are and how they come to be.

Nudging the analytical lens away from prison-based staff towards community-based practitioners requires a starting point at best. In many ways it seems logical and practical to begin with what criminal justice practitioners do in their everyday work, as this tends to illuminate what matters in community-based 
practice. But this article is not about how criminal justice work is done or the effectiveness of it, as these aspects are covered more extensively elsewhere (see Burke and Davies, 2011; Burnett and McNeill, 2005; McNeill 2006; McNeill et al., 2013). Focusing on what practitioners do is important, but this underplays the potential value of understanding, in more depth, just how and through what means these staff become adept, skilled, knowledgeable and therefore effective in their role. Underscoring this, we already have fertile literature which supports the proposition that practitioner skill-sets, practice cultures and worker attributes help to shape approaches to practice that influence desistance processes (moving away from criminal activity) in positive and meaningful ways (see Durnescu, 2014; McCulloch, 2005; McNeill, 2006; Weaver, 2015). However, these studies tend focus on experienced workers, i.e. those who have cultivated their practice through time. We know much less about working practices and arrangements that enable new staff to reach these levels of expertise in their new roles. This article will therefore attempt to address a gap in our knowledge and understanding of what occurs at the start of criminal justice careers, revealing how newly-qualified staff are currently supported and developed as new professionals within a Scottish context. This article will report on a subset of data on newly-qualified criminal justice social workers (NQCJSWs) drawn and analysed from a larger national study of newly-qualified social workers in Scotland (see XXXX, 2016).

\section{Existing research on newly-qualified criminal justice practitioners}

Scarcely anything is known in Scotland about how NQCJSWs assimilate into their new roles within the criminal justice field. This matters because professional socialisation is recognised in many fields as being a fundamental process for new employees: essentially a period during which new staff become familiar with deeply entrenched occupational cultures that can shape practice and workplace behaviours in important ways (Egan, 1989; Page, 2005). Indeed, from the limited research we have on probation cultures (mostly from studies in England and Wales), it follows that working environments seem to have notable influence on the nature and quality of criminal justice practice by shaping how this type of work is carried out, as well as having significant impact on occupational identities of those staff based in sites of community justice (Deering, 2010; Eadie and Winwin Sein, 2004; Graham, 2016; Mawby and Worrall, 2013; Robinson, 2013; Robinson et al., 2015). Interestingly, literature on professions within other criminal justice areas also suggests that newlyqualified members or new recruits undergo socialisation processes that seem to influence praxis in meaningful and important ways (for police, see Donnelly, 2014; Peace, 2006; for legal personnel, see Rowe et al., 2012; Westwood, 2015; for prison officers, see Griffin et al., 2014). Indeed, as the reader will soon discover, the findings presented in this article suggest that professional socialisation, if read as a process of inducting new employees into the way things are done, appears to occur in Scottish criminal justice working environments through largely informal and unstructured means. 
The only UK-wide study to explore experiences of newly-qualified practitioners within probation and social work settings was conducted by Peter Marsh and John Triseliotis (1996) some 18 years ago. Although somewhat dated, in the absence of significant contemporary data it will be useful here to reflect on these findings for the purposes of this article. This research was ostensibly the first major analysis of how social workers and probation officers $(n=714)$ were prepared for, and supported in, professional practice in the mid-1990s (data collected between 1992 and 1995). The chief finding was that around 85\% of participants felt well prepared for practice. Marsh and Triseliotis (1996) found that social work education (incorporating probation training) had more positive effects on levels of confidence and preparedness expressed by criminal justice practitioners than staff based in other fields of social work, e.g. community care or children and families. But whilst feeling 'prepared' was noted by many respondents, good quality induction and initial support for newly-qualified practitioners was lacking in the 1990s. Approximately $37 \%$ of participants reported having no formal period or process of induction (for those that did, the arrangements were often described as ad hoc or makeshift). Marsh and Triseliotis (1996) state that: 'whilst a minority of social (work) services departments offered an explicit programme of induction... the majority appeared to have no policy on the matter and no thought-out packages' (p172). And whilst supervision of staff (often done by senior social workers) is typically recognised as being crucial for reflective practice and professional development (Kadushin and Harkness, 2014), Marsh and Triseliotis (1996) found that 'a significant number of newly qualified staff experienced their supervision as totally instrumental in nature by focusing wholly, or almost wholly, on accountability' (p154). Around $85 \%$ of newly-qualified practitioners said they got significantly more support and guidance from informal contact with colleagues in their teams than from managers. Interestingly, Marsh and Triseliotis (1996: 136) found that participants perceived criminal justice working arrangements as overly-bureaucratic and process driven: 'there is a strong feeling that professional practice is becoming converted into a more technical or administrative process'. They conclude by suggesting that newlyqualified social workers might be: 'ready to practise when they arrive in their new jobs, but they are not fully competent to practise' (p207).

Whilst Marsh and Triseliotis (1996) provide a rare snapshot of how newlyqualified criminal justice practitioners experienced employment in the 1990s, more recent scholars highlight that similar research into lived experiences of community justice staff is still noticeably sparse (Nellis, 2003; Treadwell, 2006). However, findings from a small but loosely related body of research on the experiences of trainee probation officers in England interestingly hints at preferred (perhaps ideal) working conditions for new practitioners within criminal justice. In short, new probation recruits gained more confidence in their roles when situated in collegiate teams with rich learning cultures (Collins et al., 2009; Forbes, 2010); they seem to thrive with managers who support their professional development and meet their emotional needs (Gregory, 2007); and finally, with access to adequate learning opportunities, they tend to assimilate knowledge and skills more effectively (Jarvis, 
2002). Put simply, the evidence from England suggests that a combined triad of supportive team, manager and organisation, seems to offer the best conditions for new practitioners to thrive.

North of the border however, what matters and what makes a difference to experiences of new practitioners is much less developed. A small-scale study of criminal justice social workers $(n=12)$ in Scotland by McNeill (2001) found that experiences of training, supervision and professional development were often mixed. Although not focussing specifically on NQCJSWs, McNeill (2001: 680) suggests that in relation to the professional environment for criminal justice social workers of all lengths of experience: 'If a 'learning culture' existed at all, it was somehow fragmented and separate from the worker's routine activities; at best an adjunct to the organisation's 'ordinary' life'. In relation to developing effectiveness in practice, McNeill (2001) found that staff were more influenced by peers than managers, noting a consensus among respondents that supervision from line managers was often focused on caseload management than nurturing professional development (echoing similar findings by Marsh and Triseliotis, 1996). McNeill (2001: 681) also recognised: 'a perceived management agenda related to 'the numbers game', suggesting a perceived managerial focus on efficiency over effectiveness'. Therefore it seems that impediments or obstacles to professional development (linked to effective practice in McNeill's study) may relate in large part to organisational obsession with performance management.

\section{NQCJSW training in Scotland}

For the purpose of context, it is perhaps worthwhile to mention here the practical arrangements for training criminal justice social workers in Scotland. As many readers of this journal will know, the training of criminal justice practitioners in the UK was traditionally provided as part of social work education from the 1970s to 1996. The separation of probation and social work in England in 1997 resulted in significant divergence in how UK practitioners were subsequently trained and employed. Scotland retained (and still retains) criminal justice within the ambit of social work education, where all criminal justice social workers are still required to obtain a qualification in social work. Scottish training consists of mostly full-time university attendance with 200 days of assessed practice - usually composed of two practice placements, with no guarantee that either will be in the field of criminal justice. Social work education is currently provided by seven universities in Scotland. All qualifying courses are regulated and accredited by the Scottish Social Services Council (SSSC), who also provide bursaries for post-graduate social work students covering fees and maintenance. All social work students are required to register with the SSSC, and therefore become bound by codes of practice. Once qualified, only registered criminal justice social workers can practice in the Scottish criminal justice field.

But in contrast to current arrangements in England, where probation trainees are obliged to complete a programme dedicated to criminal justice topics, the 
Scottish social work qualification could be said to be much lighter on teaching specialist knowledge. Social work education in Scotland could be described as generic in content and purpose. The current qualification is underpinned by government standards for social work education: The Framework for Social Work Education in Scotland (Scottish Executive, 2003), where interestingly the phrase 'criminal justice' is mentioned only four times. Crucially, there is no reference to particular knowledge, skills and values relevant to criminal justice roles. Rather, students are expected simply to grasp the inter-professional nature of generic social work as one where criminal justice is presented as a branch of social work, but not necessarily a specialism in its own right.

\section{Study design and methods}

Commissioned by the Scottish Social Services Council in 2013, with data collection in 2014, XXXX et al. (2016) conducted a national study of newly-qualified social workers (staff approximately 6-12 months in post) in Scotland. They employed a mixed-method design using a national online survey questionnaire and focus groups. This research was exploratory in nature, focussing on four key aims: (1) mapping the experiences of newly-qualified social workers entering first employment from degree training programmes; (2) identifying the components that impact on their continuing professional development in the workplace; (3) examining the perspectives of recently qualified social workers in relation to their preparedness to enter professional social work practice; and (4) investigating their experiences of post-qualifying support and learning.

The study collected data from 205 newly-qualified social workers (from a total population of 555 - giving a response rate of 36\%). Of these 205 participants, 32 were employed in a criminal justice role (around $15 \%$ of the total sample). The author being a co-investigator in the main study - was able to isolate and analyse responses from all criminal justice personnel in the sample. And whilst small sample sizes can often be unrepresentative (Bryman, 2012), it should be noted that the actual number of criminal justice social workers in Scotland (around 934) represents around 15\% of the total population of social workers in Scotland (around 5909) (SSSC, 2014). However, any claims on representativeness with such small numbers must be treated with caution.

To address the geographical spread of NQCJSWs in Scotland, internetmediated-research was chosen as the most appropriate method of primary data collection for a study of this scope (see Dillman et al., 2014). A web-based questionnaire was developed and calibrated for a Scottish audience from materials generously provided by a team at Bournemouth University who conducted a similar study on newly-qualified social workers in England (see Bates et al., 2010). The survey comprised of 61 questions, incorporating Likert scales, confidence measures and space for 'free text' qualitative responses. Focus groups were also conducted in 
two Scottish cities; however, only four participants in these sessions identified themselves as being NQCJSWs. It follows that focus group data will be used here in more indicative terms.

Given the breadth of data collected, qualitative software (NVivo 10) was used to aid thematic coding, and quantitative software (IBM SPSS v.21.0) for exploring relationships between variables. And whilst not unduly sensitive, ethical consideration was given to the potential for individual cases to be discussed, and for employer practices to be exposed and criticised. Ethical approval was sought from XXXX ethics committee before any research commenced. In terms of recruitment, all newly-qualified social workers in Scotland were emailed directly from the Scottish Social Services Council register. Maximum variation sampling was used where all and only newly-qualified social workers who graduated at least six-months prior to January 2014 were included. This meant that all participants had some experience in their new professional roles before participating in this study.

\section{Findings}

\section{(i) Feeling prepared and measures of confidence}

As a general opening question, participants were asked to rate the extent to which they felt their qualifying courses had prepared them for the 'realities of frontline practice'. $33.3 \%$ reported that higher education had provided 'good' preparation, whereas $54.1 \%$ suggested their preparation was 'adequate'. The remaining $12.6 \%$ felt their preparation was 'poor'. These results indicate a general skew towards feeling more prepared than not. Although for some participants it could be argued that academic ability, the quality of teaching on their course, the quality of practice learning experiences, their existing knowledge of criminal justice (whether gained on pre-qualifying courses or absorbed from practice placements), as well as their immediate experiences of employment - perhaps contributed to their own subjective sense of preparedness in this case. Interestingly, of those participants who rated their preparation as 'poor', none had received a criminal justice placement as part of their learning (most, incidentally, were placed in children and families settings). This suggests that these particular NQCJSWs were possibly disadvantaged by their lack of pre-exposure to practice cultures within criminal justice settings.

In many ways a more nuanced picture of what 'preparedness' meant to NQCJSWs emerged in qualitative text responses from a series of follow-up questions on their university education. In one example, a participant pointed to the value in having simulated experiences of criminal justice settings such as court rooms, suggesting this was: 'the best preparation I could have had... this one small piece of the course is what has set me up best for my current role' (NQCJSW8). Indeed, consensus from other qualitative responses would suggest that NQCJSWs who gained pre-employment experiences of criminal justice settings whilst on practice placements had better impressions of preparedness overall. As one such participant 
with this experience noted: 'Everything just felt familiar, just like being on placement again but paid [as a new criminal justice staff member]... I just got on with it' (NQCJSW25). So it seems that pre-exposure to criminal justice environments during social work education may have some merit in preparing NQCJSWs for what lies ahead.

More specifically however, the questionnaire sought to explore other dimensions of 'preparedness' by measuring confidence levels associated with typical skills, tasks and processes, as prescribed by the National Occupational Standards for Social Work (NOS) (TOPPS, 2002). In this section of the survey, participants were invited to rate how confident they felt against each recognised standard (See Table $1)$.

Table 1 NQCJSW levels of confidence across units of NOS

\begin{tabular}{llccc}
\hline National Occupational Standards & $\begin{array}{l}\text { Not at all } \\
\text { confident }\end{array}$ & $\begin{array}{l}\text { Quite } \\
\text { Confident }\end{array}$ & Confident & $\begin{array}{l}\text { Very } \\
\text { Confident }\end{array}$ \\
\hline $\begin{array}{l}\text { Assessing needs and options to recommend a } \\
\text { course of action }\end{array}$ & $0.00 \%$ & $15.38 \%$ & $50.00 \%$ & $34.62 \%$ \\
\hline $\begin{array}{l}\text { Working with individuals and communities } \\
\text { to help them make informed decisions }\end{array}$ & $0.00 \%$ & $19.23 \%$ & $50.00 \%$ & $30.77 \%$ \\
\hline $\begin{array}{l}\text { Liaising with other teams, professionals, } \\
\text { networks and systems }\end{array}$ & $8.00 \%$ & $8.00 \%$ & $52.00 \%$ & $32.00 \%$ \\
\hline $\begin{array}{l}\text { Advocating with and on behalf of individuals } \\
\text { and communities }\end{array}$ & $0.00 \%$ & $23.08 \%$ & $50.00 \%$ & $26.92 \%$ \\
\hline $\begin{array}{l}\text { Working with individuals and communities } \\
\text { to achieve change }\end{array}$ & $3.85 \%$ & $15.38 \%$ & $57.69 \%$ & $23.08 \%$ \\
\hline $\begin{array}{l}\text { Managing and being accountable for your } \\
\text { own work }\end{array}$ & $3.85 \%$ & $11.54 \%$ & $65.38 \%$ & $19.23 \%$ \\
\hline $\begin{array}{l}\text { Assessing and managing risks to individuals } \\
\text { and communities }\end{array}$ & $0.00 \%$ & $26.92 \%$ & $53.85 \%$ & $19.23 \%$ \\
\hline $\begin{array}{l}\text { Assessing and managing risks to self and } \\
\text { colleagues }\end{array}$ & $7.69 \%$ & $15.38 \%$ & $53.85 \%$ & $23.08 \%$ \\
\hline $\begin{array}{l}\text { Working with groups to promote individual } \\
\text { development and independence }\end{array}$ & $0.00 \%$ & $40.00 \%$ & $40.00 \%$ & $20.00 \%$ \\
\hline $\begin{array}{l}\text { Preparing, producing, implementing and } \\
\text { evaluating plans }\end{array}$ & $3.85 \%$ & $34.62 \%$ & $46.15 \%$ & $15.38 \%$ \\
\hline $\begin{array}{l}\text { Supporting the development of networks to } \\
\text { meet assessed needs }\end{array}$ & $11.54 \%$ & $30.77 \%$ & $30.77 \%$ & $26.92 \%$ \\
\hline $\begin{array}{l}\text { Researching, analysing and using current } \\
\text { knowledge of best practice }\end{array}$ & $3.85 \%$ & $38.46 \%$ & $42.31 \%$ & $15.38 \%$ \\
\hline $\begin{array}{l}\text { Preparing for, and participating in decision } \\
\text { making forums }\end{array}$ & $3.85 \%$ & $42.31 \%$ & $34.62 \%$ & $19.23 \%$ \\
\hline $\begin{array}{l}\text { Responding to crisis situations } \\
\text { Managing complex ethical issues, dilemmas } \\
\text { and conflicts }\end{array}$ & $3.85 \%$ & $53.85 \%$ & $26.92 \%$ & $15.38 \%$ \\
\hline $\begin{array}{l}\text { Contributing to the management of resources } \\
\text { and services }\end{array}$ & $23.08 \%$ & $30.77 \%$ & $26.92 \%$ & $19.23 \%$ \\
\hline
\end{tabular}


Table 1 demonstrates that most participants felt confident across the majority of national occupational standards, with strong levels of confidence noted for assessing needs, working with individuals to make informed decisions, interdisciplinary liaison, advocacy, and working with people to achieve change. Participants felt least confident in contributing to the management of resources and services, perhaps due to the fact that criminal justice staff are less likely to be involved in the administration of care packages (more commonly associated with social workers in community care settings). But these findings align well with Gregory's (2007) study of newly-qualified probation officers in England, where firm majorities felt confident or very confident across a range of areas such as supporting people with their problems, building relationships and communication. In many ways these findings also buttress existing literature on the importance of relational skills in criminal justice practice (see McNeill et al., 2005; Weaver and McNeill, 2010).

\section{(ii) Mentoring, induction, supervision and support within first year of employment}

Whilst there is no acknowledged scheme for mentoring NQCJSWs in Scotland, around $84.6 \%$ of participants said they had no formal professional connection with any member of non-management staff. This is significant because around $80.7 \%$ of participants felt that support and guidance from colleagues was seen to be 'very important' in their first year of practice (a finding echoed in Marsh and Triseliotis, 1996). This emerged as a strong theme in focus group discussions where participants said they relied more on experienced colleagues than managers for professional advice. As one participant put it: 'I always go to [participant's colleague] first... cos he knows his stuff, you know, better than [participant's manager]' (NQCJSW4). Further comments confirmed that NQCJSWs often turned to peers for informal discussion and opportunities to reflect on their experiences - as one participant noted: 'all that experience in one team... yeah I can talk about anything, especially difficult cases... I'm learning [from peers] everyday' (NQCJSW3). These findings align in many ways with McNeill's (2001) study which found that criminal justice social workers often regarded peer-to-peer learning as crucial for professional development. Similar findings emerged in a study of newlyqualified probation officers conducted by Forbes (2010) which found that support and guidance from colleagues was regarded as crucial, especially for new staff at the start of their careers.

Yet without a recognised mentor as they entered their professional roles, the majority of NQCJSWs regarded their induction phase as adequate. NQCJSWs were asked to rate the quality of their induction experiences from excellent to poor (see Table 2).

Table 2 NQCJSW quality of induction

\begin{tabular}{ll}
\hline Rating & NQCJSW \% (n=32) \\
\hline Excellent & 15.3 \\
Very Good & 11.5 \\
Satisfactory & 30.7
\end{tabular}




Not very good $\quad 30.7$

Poor 11.5

Whilst the majority of participants felt satisfied with the quality of their induction, just over a third rated their experience in negative terms. Interestingly, these findings reflect what Marsh and Triseliotis (1996) found some 18 years ago, and what Gregory (2007) found more recently, namely that a proportion of entrants (half in Gregory's study) felt they were not supported into their new roles sufficiently. Yet, when asked for more detail (in free-text responses) on what induction often entailed for NQCJSWs, a fairly inconsistent picture emerged in terms of what participants experienced and what they viewed as being important. Some were satisfied with a basic introduction to their organisation: 'got one day [agency] induction, that's enough for me' (NQCJSW10); others wanted more than just a straightforward primer: 'I thought it would be a week or two intensive, but just got half-a-day and straight to work after' (NQCJSW14). Some were simply given policy documents to read; others received a structured induction package. But as Scotland does not have a nationally agreed programme of induction, variation in these findings across 32 local authorities is perhaps unsurprising.

But how NQCJSWs were supported in their current role was captured by a series of questions exploring experiences of supervision from a line-manager typically a senior social worker. As mentioned earlier, supervision in social work is recognised as being crucial and necessary to ensuring that accountable and effective practice is undertaken by the practitioner (Kadushin and Harkness, 2014). In this study participants were asked to rate the quality of supervision provided by their line managers (see Table 3).

Table 3 NQCJSW quality of supervision

\begin{tabular}{ll}
\hline Rating & NQCJSW \% $(\mathrm{n}=32)$ \\
\hline Excellent & 15.3 \\
Very good & 30.7 \\
Satisfactory & 34.6 \\
Not very good & 19.2 \\
Poor & 0 \\
\hline
\end{tabular}

On the face of it, findings in Table 3 suggests that the majority of NQCJSWs felt satisfied with the quality of supervision from their line manager. This marks a significant improvement from the Marsh and Triseliotis (1996) study, where approximately half of their sample reported poor and inconsistent supervision. Positive findings also emerged when participants were asked to rate their experience of being able to critically reflect on practice whilst in supervision (see Table 4), where approximately two-thirds felt satisfied with the opportunities to do so.

Table 4 Opportunities for critical reflection in supervision

\begin{tabular}{ll}
\hline Rating & NQCJSW \% $(\mathrm{n}=32)$ \\
\hline Excellent & 19.2
\end{tabular}




\begin{tabular}{ll} 
Very good & 19.2 \\
Satisfactory & 23 \\
Not very good & 30.7 \\
Poor & 7.6 \\
\hline
\end{tabular}

Yet despite the positive reporting here on the quality of supervision, participants in focus group discussions felt that supervision was used by managers solely for the purpose of caseload management. As one participant put it: 'we meet every 3 weeks or something, but its only to talk about cases... she [participant's manager] never asks me how i'm doing' (NQCJSW1). Negative comments also emerged in free-text responses within the main online survey, where many felt that supervision provided little space for critical reflection on cases (despite this element receiving positive ratings by two thirds in Table 4). As one participant noted: 'too much time spent on KPIs [key performance indicators]; leaves no time [in supervision] to analyse practice properly' (NQCJSW23). A clear consensus emerged in reply to a supplementary online question, again using free-text responses, asking participants to comment on what they thought the main purpose of supervision was. Here the majority mentioned phrases such as: 'caseload management', 'managing work', 'workload', with a few positive exceptions such as 'personal development' and 'addressing training needs'. These findings seem to suggest a mixed picture in relation to experiences and perceptions of supervision. This may be to do with variation in local practices, as there is no nationally recognised process or guidance for what supervision ought to include for newly-qualified practitioners. Or it may, in some ways, reveal the limits of using online questionnaires as the primary method to explore what is, in effect, a largely subjective experience.

Unexpected findings emerged when participants were asked about what they would like to see changed about supervision. The majority of NQCJSWs expressed a wish, in free-text responses, for their emotions to be explored in more depth. As one participant put it: 'I'd like to be able to open up a little more' (NQCJSW1), whilst another simply suggested: 'to explore feelings' (NQCJSW3). Interestingly, some participants referred to more serious problems where managers would misread their emotional concerns as a reflection of professional incompetence. As one focus group participant stated: 'she [manager] said it's probably a diary issue, but I told her I wasn't coping... she said, 'OK, let's look at your diary then'... she didn't listen' (NQCJSW3). One NQCJSW called for supervision to be: 'a safe space, without fear of portraying myself as being unable to cope with the demands of the job, which can often be misinterpreted as this when discussing and reflecting' (NQCJSW12). The notion of safe space emerged in a similar free-text response from another participant who suggested supervision should be: 'An opportunity for reflection... but it is not a safe environment to do so. There is a fear of being belittled if I express my views' (NQCJSW7). These findings were surprising, as participants were not prompted to comment specifically on emotional issues; however, they do suggest that the emotional impact of work within community justice contexts is perhaps underplayed (for recent commentary on this point, see Knight et al., 2016). Indeed, harnessing and developing the 'soft skills' associated with emotional literacy are 
thought to be effective in working with criminal justice service users (see Knight, 2014; also Mawby and Worrall, 2013). But the lack of emotional recognition in supervision emerges in other studies where more practical aspects of the job seem to take precedence over feelings. For example, Gregory (2007) found that the majority of newly-qualified probation officers in her study regarded the purpose of supervision as being skewed more towards performance indicators and caseload management. Similar findings emerged in McNeill (2001: 681), where supervision was often considered to be inconsistent in terms of frequency and content, and generally seen to be more 'superficial rather than analytical'.

\section{(iii) Professional development}

The final section of the online survey focused on experiences of training and professional development opportunities for new staff in criminal justice social work. NQCJSWs are required by the workforce regulator, the Scottish Social Services Council (SSSC), to complete what are known as Post Registration Training and Learning requirements (PRTL). New staff are required to complete 24 days (144 hours) of activity designed to: 'advance the newly qualified social worker's professional development or contribute to the development of the profession as a whole' (SSSC, 2011: 3). The purpose here, according to the SSSC, is to: 'ensure that all NQSWs undertake training and learning to assist them to consolidate their social work skills, knowledge and values' (SSSC, 2011: 3). But the regulator states that the 'training and learning required... does not have to be formally certified' (SSSC, 2011: 7). This degree of ambiguity over what constitutes evidence of learning was captured well during focus group discussions, where it emerged that participants were not only confused by official guidance, but many felt that few learning opportunities were made available in their workplace settings. As one participant stated: 'yeah, you're just left to sort out your own learning, which I understand, but I don't get any protected time or support from my senior [manager] to do this' (NQCJSW2). Another participant referred to having little time for professional development: 'just can't be done; my workload is just a killer... and that's the thing, you know, I'd benefit from learning more' (NQCJSW3). So even when NQCJSWs are motivated to seek out their own learning opportunities, it seems that some organisations and managers are not providing enough support and space for these staff to pursue this.

In Scotland there is no nationally approved training pathway for NQCJSWs. The majority of NQCJSWs commented that training offered to them by employers often meant instruction on practical processes, such as software to assist and log risk assessments, offender management protocol, government briefings on risk management, and report writing for courts. The majority of participants (73\%) had engaged with training departments within their first year of employment; although many felt that training was often pitched well-below their ability as degree-level graduates, as one participant noted: 'a lot of the time it is very basic' (NQCJSW3), 
whilst another participant stated: 'I thought we'd get to learn about more difficult stuff, you know, about law and punishment... kinda building on what we got from uni' (NQCJSW1). More meaningful learning opportunities, according to the majority of NQCJSWs, were often gained through shadowing colleagues, observing events (such as attending court), engaging with academic material and having reflective discussions about practice with peers. As one participant stated: 'I get more from watching and talking about practice... the training we get, well it's all about risk, nothing really about working with people' (NQCJSW4). The impression left for most NQCJSWs in this study was typically that training offered by employers was not meeting their professional development needs.

When asked what they would like to receive more training on, many NQCJSWs (within free-text responses) called for more specific input on areas such as 'desistance models', 'effective interventions', 'criminal justice policy', 'criminological theory' and 'criminal law' (similar developmental needs were identified by criminal justice staff in McNeill's (2001) study some 15 years ago!) Very few participants called for more input on agency processes or protocol. In essence, these findings do appear to suggest that most learning at the post-qualified stage in Scotland is largely self-directed, unstructured and weighted towards matters of organisational policy and procedure, rather than nurturing professional, intellectual and personal development within a specific criminal justice context.

\section{Conclusion}

The key findings from this study indicate that (1) the majority of NQCJSWs felt well-prepared for the perceived realities of front-line practice; (2) the majority felt confident across a number of National Occupational Standards in social work, especially communication and assessment skills required to work effectively with service users; (3) the majority placed significant value on support and guidance from colleagues and peers, often in preference to what they got from managers; (4) overall experiences of induction and supervision were reported with significant variation across Scotland; (5) for many NQCJSWs, supervision sessions seemed to be dominated by over-emphasis on caseload management, rather than professional development; (6) many NQCJSWs appeared to receive few structured opportunities to develop their skills and knowledge through activities and training designed for their status as degree-level graduates; and finally (7), that for many NQCJSWs, the emotional toll of working with offenders was significantly underplayed by social work managers. In sum, these findings suggest that whilst the majority of NQCJSWs in this study felt prepared for entering the field of community justice, and therefore confident in their skills and abilities to work with offenders, many employers did not appear to offer the types of support, training and development opportunities that many NQCJSWs perhaps expected. A striking feature of these findings is that they appear to resemble, albeit indicatively, what Marsh and Triseliotis (1996) found in their study of 'readiness to practice' some 18-years ago: namely a well-prepared workforce keen to develop their skills and knowledge, but restricted by employer 
demands on them to engage more in criminal justice processes than criminal justice pedagogy.

In a context where criminal justice staff are increasingly expected to engage in more complex interventions, write more complex reports and do more complex risk assessments, it is perhaps no surprise that employers in Scotland tend to opt for more 'techno-rationalist' (Lankshear, 1997) approaches to professional learning and development. As the findings here show, performance management, accountability and efficiency appear to underscore the types of training and learning opportunities made available to NQCJSWs. This leaves other aspects of professional socialisation, such as absorbing local practice cultures or acquiring new knowledge, to occur through more informal means: casual interactions with colleagues and peers, observing events, self-directed reading, shadowing experienced workers - in short, learning on the job. Scholars such as Durnescu (2014) suggest that staff in criminal justice roles progressively absorb and inculcate elements of diverse organisational cultures and practices at different rates through a continuous process of professional socialisation over the course of their careers. The Scottish example here certainly reveals a fluid and variable approach to socialising new recruits into professional practice, with no specific blueprint for induction, training and supervision. Indeed, if professional development somehow levels-out, leading to a 'unified practice' as suggested by Durnescu (2014), then perhaps NQCJSWs mixed experiences at the moment are best explained by local variations in arrangements for training and support, rather than representing evidence of deliberate efforts by certain managers or organisations to constrain professional progress.

Striking a balance between what employers want and what employees expect, ought to be explored in more depth, perhaps with further research combining the voice of managers with much deeper types of data from practitioners (e.g. from in-depth interviews or longitudinal cohort surveys). As a conceptual route forward however, Graham (2016) suggests that we ought to think about harmonising aspects of practice that often stand in opposition both practically and theoretically. In her view, 'Combining professionalisation with professional socialisation may conserve institutional memory and the culture of longstanding attitudes and approaches' (Graham, 2016: 125). Indeed, the traditions, history and practice cultures of probation and criminal justice social work often persist in shaping practitioner dispositions, and therefore practice behaviours, in particular and important ways (see XXXX, 2015). Drawing on the Bourdieusian concept of habitus, XXXX (2015) suggests that by grafting values, skills, and knowledge from welfare-oriented practice cultures, practitioners often build appropriate armoury to help resist unpleasant aspects of techno-rational managerialism whilst engaging in forms of practice driven more deeply by social justice than punitive intent or agency will. In many ways, Scottish criminal justice social work could harness the agentic capacity of inculcated values of penal welfarism, often found and celebrated within local practice cultures (XXXX, 2015; Robinson, 2008), and combine these qualities with more emphasis on criminal justice as a specialist branch of social work, with distinct 
areas of knowledge that ought to be developed incrementally - starting at university and continued into employment. Only then might the professional socialisation of NQCJSWs be something assembled with better structure and purpose, offering more consistent and durable form to the constitution, training and development of professional criminal justice practitioners - helping them to cope better, even, with the techno-rationalist environment they currently find themselves in.

\section{Acknowledgments}

I am very grateful to Hannah Graham and Trish McCulloch for comments on a previous draft of this article. Thanks also extend to Lynn Sheridan and Stephen Webb who gave permission for data to be used from our research on newly-qualified social workers.

\section{Funding Acknowledgment}

This article reports on a sub-set of data from a study commissioned by the Scottish Social Services Council. The views expressed in this article are not necessarily those of the Scottish Social Services Council.

\section{References}

XXXX (2014) AUTHORS OWN

XXXX (2015) AUTHORS OWN

XXXX (2016) AUTHORS OWN

Bates N, Immins T, Parker J, Keen S, Rutter L, Brown K and Zsigo S (2010) Baptism of fire: The first year in the life of a newly qualified social worker. Social Work Education 29(2): 152-170.

Bryman A (2012) Social Research Methods (4th Edition). Oxford: Oxford University Press.

Burke L and Davies K (2011) Introducing the Special Edition on Occupational Culture and Skills in Probation Practice. European Journal of Probation 3(3): 114.

Burnett R and McNeill F (2005) The place of the officer-offender relationship in assisting offenders to desist from crime. Probation Journal 52(3): 221-242.

Collins S, Coffey M and Cowe F (2009) Stress, support and well-being as perceived by probation trainees. Probation Journal 56(3): 238-256.

Crewe B (2011) Soft Power in Prison: Implications for Staff-prisoner Relationships, Liberty and Legitimacy. European Journal of Criminology 8(6): 455-468.

Deering J (2010) Attitudes and Beliefs of Trainee Probation Officers: a New Breed? Probation Journal 57(1): 9-26. 
Dillman DA, Smyth JD and Christian LM (2014) Internet, Phone, Mail, and MixedMode Surveys: The Tailored Design Method (4th Edition). Oxford: Wiley.

Donnelly D (2014) The Scottish Police Officer. Abingdon, Oxon: Routledge.

Durnescu I (2014) Probation skills between education and professional socialization. European Journal of Criminology 11(4): 429-444.

Eadie T and Winwin Sein S (2004) Probation Officer Development and Retention: A Longitudinal Study. Questionnaire One. Tamworth: Midlands Consortium.

Egan JM (1989) Graduate school and the self: A theoretical view of some negative effects of professional socialisation. Teaching Sociology 17(2): 200-208.

Forbes D (2010) Probation in Transition: A Study of the Experiences of Newly Qualified Probation Officers. Journal of Social Work Practice 24(1): 75-88.

Garland D (2001) The Culture of Control: Crime and Social Order in Contemporary Society. Oxford: Oxford University Press.

Graham H (2016) Rehabilitation Work: Supporting Desistance and Recovery. London: Routledge.

Gregory M (2007) Probation Training: Evidence from Newly Qualified Officers. Social Work Education 26(1): 53-68.

Griffin ML, Hogan NL and Lambert EG (2014) Career Stage Theory and Turnover Intent Among Correctional Officers. Criminal Justice and Behavior 41(1): 4-19.

Jarvis S (2002) A critical review: integrating knowledge and practice. British Journal of Community Justice 1(1): 65-78.

Kadushin A and Harkness D (2014) Supervision in Social Work. New York: Columbia University Press.

Knight C (2014) Emotional Literacy in Criminal Justice: Professional Practice with Offenders. Houndsmills: Palgrave Macmillan.

Knight C, Phillips J and Chapman T (2016) Bringing the feelings back: returning emotions to criminal justice practice. British Journal of Community Justice 14(1): $45-58$.

Lankshear C (1997) Language and the new capitalism. International Journal of Inclusive Education 1(4): 309-321.

Lerman AE and Page J (2012) The State of the Job: An Embedded Work Role Perspective on Prison Officer Attitudes. Punishment E Society 14(5): 503-529.

Liebling A (2000) Prison Officers, Policing and the Use of Discretion. Theoretical Criminology 4(3): 333-357.

Marsh P and Triseliotis J (1996) Ready to Practise? Social Workers and Probation Officers: Their Training and First Year in Work. Aldershot: Avebury.

Mawby RC and Worrall A (2013) Doing Probation Work: Idendity in a criminal justice occupation. Abingdon, Oxon: Routledge.

McCulloch T (2005) Probation, social context and desistance: retracing the relationship. Probation Journal 52(1): 8-22.

McNeill F (2001) Developing effectiveness: Frontline perspectives. Social Work Education 20(6): 39-62

McNeill F (2006) A Desistance Paradigm for Offender Management. Criminology and Criminal Justice 6(1): 39-62. 
McNeill F, Batchelor S, Burnett R and Knox J (2005) 21st Century Social WorkReducing Re-Offending: Key Practice Skills. Edinburgh: Scottish Executive.

McNeill F, Farrall S, Lightowler C and Maruna, S (2013) Discovering Desistance: Reconfiguring Criminal Justice? Scottish Justice Matters 1(2): 3-6.

Nellis M (2003) Probation training and the community justice curriculum. British Journal of Social Work 33(7): 943-959.

Page G (2005) Professional socialisation of valuers: What the literature and professional bodies offers. International Education Journal 5(5): 105-116.

Peace RJ (2006) Probationer training for neighborhood policing in England and Wales: fit for purpose? Policing: An International Journal of Police Strategies $\mathcal{E}$ Management 29(2): 335 - 346.

Phelps MS (2016) Mass probation: Toward a more robust theory of state variation in punishment. Punishment $\mathcal{E}$ Society. Epub ahead of print 10 May 2016. DOI: $10.1177 / 1462474516649174$.

Robinson A (2013) Transforming rehabilitation: transforming the occupational identity of probation workers? British Journal of Community Justice 11(2-3): 91 101.

Robinson G (2008) Late Modern Rehabilitation: The Evolution of a Penal Strategy. Punishment and Society 10(4): 429-445.

Robinson G (2016) The Cinderella complex: Punishment, society and community sanctions. Punishment $\mathcal{E}$ Society 18(1): 95-112.

Robinson G, Burke L and Millings M (2015) Criminal justice identities in transition: the case of devolved probation services in England and Wales. British Journal of Criminology. Epub ahead of print 19 May 2015. DOI: 10.1093/bjc/azv036.

Robinson G \& McNeill F (Eds) (2016) Community Punishment: European Perspectives. London: Routledge.

Rowe M, Murray M and Westwood F (2012) Professionalism in pre-practice legal education: an insight into the universal nature of professionalism and the development of professional identity. The Law Teacher 46(2): 120-131.

Scottish Executive (2003) The Framework for Social Work Education in Scotland. Edinburgh: Scottish Executive.

Scottish Social Services Council (2011) Post Registration Training and Learning Requirements for Newly Qualified Social Workers (NQSWs): Guidance Notes for NQSWs. Dundee: Scottish Social Services Council.

TOPPS (2002) The National Occupational Standards and Key Skills for Social Work. Leeds: TOPPS UK Partnership.

Treadwell J (2006) Some Personal Reflections on Probation Training. The Howard Journal 45(1): 1-13.

Weaver B (2015) Offending and Desistance: The Importance of Social Relations. London: Routledge.

Weaver B and McNeill F (2010) Travelling Hopefully: Desistance Research and Probation Practice. In Brayford J, Cowe F and Deering F (eds) What Else Works? Creative Work with Offenders. Cullompton: Willan Publishing, pp. 3660.

Westwood F (2015) Cultivating judgment: the ability to exercise professional judgment matters. The Journal of the Law Society of Scotland 60(10): 18-27. 
Submitted to the Probation Journal - Accepted October $14^{\text {th }} 2016$

Word count: 6984 